\section{Post-vasectomy depression: a case report and literature review}

\author{
Subahani Shaik, Ravi Philip Rajkumar \\ Department of Psychiatry, Jawaharlal \\ Institute of Postgraduate Medical \\ Education and Research, Dhanvantari \\ Nagar, Pondicherry, India
}

toms occur only in a minority of patients; in most men, vasectomy is not associated with an excess of psychological morbidity compared with other contraceptive methods. ${ }^{5}$ Pre-existing marital or psychological instability may place men at a higher risk of such complications. ${ }^{6}$ In this paper, we present the unusual case of a man who developed chronic, difficultto-treat major depression following a noscalpel vasectomy, and review the existing literature addressing the psychological adverse effects of this procedure, with a specific focus on depression.

\section{Abstract}

Vasectomy is a commonly performed and relatively safe procedure, with low reported rates of psychological morbidity, though there is some variability across studies. Depression following a vasectomy is relatively infrequent. A married man aged 30 developed a chronic depressive episode, lasting four years and resistant to an adequate trial of fluoxetine, following a vasectomy. His depression was heralded by a post-operative panic attack, and was accompanied by medically unexplained symptoms and the attribution of all his symptoms to the procedure - a belief that was shared by his family. Psychological complications of vasectomy have generally been studied under four heads: sexual dysfunction, effects on marital relationships, chronic post-operative pain, and other complications including anxiety and depression. These complications have generally been reported at higher rates in developing countries, and are linked to poor knowledge about the procedure and inadequate pre-operative counseling. The implications of the existing literature for the patient's current complaints, and the mechanisms and risk factors involved, are discussed in the light of existing research. Suggestions for the prevention and treatment of post-vasectomy depression are also outlined.

\section{Introduction}

Vasectomy is a relatively minor surgical procedure which has been used by over 40 million couples around the world as a permanent method of contraception. Though the procedure is generally safe, it is associated with significant morbidity in about $1 \%$ of patients. 1,2 Most studies of post-vasectomy complications have focused on physical complaints, such as post-operative pain. However, existing research suggests that the procedure may also be followed by psychological complications, such as depression, irritability, and medically unexplained somatic symptoms.$^{3,4}$ Such symp-

\section{Case Report}

Our patient, aged 30 , a high school graduate for the past seven years, presented to our clinic with the chief complaints of pervasive sad mood and fatigue. He was apparently normal until four years before, when he was encouraged to undergo a vasectomy by a local doctor, as he already had three children and did not wish to have any more. His family were not in favor of the procedure and felt that it would be harmful to his health, but he was convinced by his doctor and elected to undergo the procedure. He did not receive any formal pre-operative counseling. Immediately after leaving the operating theatre following the procedure, he experienced acute symptoms of anxiety, palpitations, increased sweating and tremors for which no medical cause could be found, suggestive of a panic attack. These symptoms resolved within an hour, but from that day onwards, he found himself feeling tired throughout the whole day, and unable to do his work. He reported chest and body pains for which no medical cause could be found, and which were worsened by exertion. He felt sad for most of the day, and could not find any reason for the same. His sleep and appetite were reduced. He did not report any sexual dysfunction, but complained that his wife was less interested in sexual relations following the procedure. There were occasional death wishes and suicidal ideas secondary to his chronic symptoms and unemployment, but he had made no plans or attempts to end his life.

There was no post-operative pain, swelling, or any other surgical complication. However, he felt his family had been right about the risks of the procedure, and he had made an error by consenting to it; he attributed his current plight to his vasectomy. He had already complaints, and had received an adequate trial of fluoxetine, $20 \mathrm{mg} /$ day for 6 months, without significant improvement. He was premorbidly well-adjusted. There was a past history of presumed viral encephalitis at the age of 13 , formerly working as a manual laborer, married consulted a private practitioner for the above
Correspondence: Ravi Philip Rajkumar, Department of Psychiatry, Jawaharlal Institute of Postgraduate Medical Education and Research (JIPMER), Dhanvantari Nagar, Gorimedu Pondicherry 605006, India.

Tel.: +91.413.229.6402.

E-mail: ravi.psych@gmail.com

Key words: depression, vasectomy, sterilization, anxiety, counseling.

Contributions: SS, conducted a thorough diagnostic evaluation and in-depth interview of the patient and his family; RPR was the supervising consultant, guided the formulation of the patient's management plan, and conducted the literature review.

Conflict of interests: the authors declare no potential conflict of interests.

Received for publication: 27 May 2014.

Accepted for publication: 2 July 2014.

This work is licensed under a Creative Commons Attribution NonCommercial 3.0 License (CC BYNC 3.0).

(C) Copyright S. Shaik and R.P. Rajkumar, 2014

Licensee PAGEPress, Italy

Mental Illness 2014; 6:5494

doi:10.4081/mi.2014.5494

which he had recovered from without any lasting deficits. His father had received treatment for an unspecified mental illness in the past, but no reliable information about the nature of this illness could be obtained. There was no previous marital disharmony.

Physical examination, including genital examination, was unremarkable. Mental status examination revealed a depressed affect, reduced psychomotor activity, low self-esteem (due to his current unemployment), and attribution of all his symptoms to his vasectomy. This attribution was shared by his family and did not amount to a delusion. There were no cognitive deficits. His diagnosis as per ICD-10 criteria was moderate depression without somatic syndrome.

\section{Discussion}

Our patient presented with difficult-to-treat, chronic depression following a vasectomy. Psychological complications of vasectomy have been relatively under-researched, and there is some evidence that simple questionnaires may miss important aspects of psychological morbidity. For example, Wolfers reported that 10 out of 82 men $(12 \%)$ in her sample reported psychosexual problems when interviewed by a 
professional, whereas only $1-3 \%$ of men reported them when screened using a questionnaire. ${ }^{6}$

The history of vasectomy in relation to mental health is long and controversial. It was once advocated as a treatment method for sexually violent offenders, ${ }^{7}$ and compulsory vasectomy for mentally ill men was one of the components of the eugenics movement, which reached its peak during the Nazi regime. ${ }^{8}$ In the years following the Second World War, these indications were quietly abandoned for the most part, and vasectomy was principally used as an elective method of sterilization. ${ }^{9}$ Though concerns were raised about possible adverse psychological effects, such as sexual dysfunction and regret following the procedure, it was argued that these effects could be prevented by careful pre-operative counselling. 10

Early formulations of the psychological effects of vasectomy were based on the Freudian concept of castration anxiety, 6 a view that has been endorsed by some researchers. ${ }^{11,12}$ However, most research has been atheoretical, and has focused on sexual and marital complications following vasectomy. Studies of other psychological sequelae are fewer. With regard to sexual functioning, several authors have reported either no effect, ${ }^{13-16}$ or a slight improvement in sexual performance following the procedure.17,18 Most of this information is based on patients' own reports, though other authors have reported a variety of sexual side effects, including erectile dysfunction in $2-5 \%, 19,20$ premature ejaculation in $16.7 \%, 20$ and decreased libido in $4-19 \% .19,21,22$ Studies of vasectomy acceptors in India have reported rates of sexual dysfunction ranging from 3.3\%-21.7\%.20,23-25 The reasons for these significant variations are discussed below. Men with long-standing, pre-vasectomy sexual dysfunction do not generally show improvement after the procedure. 6,26

In parallel with the effects on male sexual functioning described above, most researchers have reported an improvement, $12,14,26-28$ or no change, 15,17 in marital satisfaction or stability and these improvements have generally been in the sexual domain. However, it has been observed that, in the presence of pre-operative marital disharmony or conflict, difficulties tend to persist or worsen following a vasectomy.6,26 Furthermore, regret about the procedure and its irreversibility can affect 2.6-10\% of couples, $14,22,29$ and can be related to poor communication and power imbalances in the couple.

Testicular pain is a well-recognized consequence of vasectomy, but its relationship to mental health is obscure. While some authors ascribe a contributory role to psychological factors such as depression and substance abuse, 2,4 others view depressive symptoms as a consequence, rather than a cause, of chronic pain. ${ }^{30}$ A study from Chandigarh, India, found that 7 of 82 men $(8.5 \%)$ had persistent pain at the operative site following a vasectomy. Intriguingly, the majority of this sample (44/82, $54 \%$ ) also reported other physical complaints for which no medical cause could be found. These symptoms included weight loss, indigestion, giddiness, breathlessness and leg pain, and were severe in 7 (8.5\%) of men. ${ }^{24}$

Depression and anxiety, despite their obvious relationship to pain and sexual dysfunction, have been relatively under-studied. Depressed mood has been reported by $8.5 \%$ of men in an Indian study, and nervousness by $6.1 \%{ }^{24}$ A study from China found that the odds of both anxiety (OR 4.79) and depression (OR 3.97 ) were increased in men who had undergone a vasectomy; 31 this study used continuous, rather than categorical, measures of anxious and depressive symptoms. A British study reported two cases of severe depression (1.4\%) in 145 men following vasectomy; 26 both these men had a past history of depression which they had not disclosed at the time of the procedure. A postal survey of British men six years after undergoing a vasectomy found very low rates of self-reported depression (4 out of 1508 responses received; $0.3 \%$ ); however, three men in this study $(0.2 \%)$ reported improvement of a pre-existing depression. 32

The origins and determinants of these psychological and sexual problems are complex. Setting aside the debatable but replicated finding that some men view vasectomy as a symbolic castration, 11,12 men who have undergone a vasectomy experience a variety of psychological changes. These include concerns about masculinity and male identity, ${ }^{5}$ fears of spousal infidelity, 33 fears about the loss of living children through death or divorce, 34 and conflicts with religious and moral values. ${ }^{35}$ These changes result in an overall adverse effect on psychological adjustment in some men, as assessed using psychometric instruments. ${ }^{12,36,37}$ In the presence of other risk factors, listed in the following section, such changes could trigger the onset of depression, anxiety, or sexual dysfunction.

A variety of risk factors for post-vasectomy psychological morbidity have been described in the literature. These include pre-existing marital and sexual difficulties, pre-existing mental illness, ${ }^{6,26}$ premorbid neuroticism, ${ }^{20}$ older age, greater education, and higher income, 31 and negative views of the operation's effects on health. ${ }^{22}$ However, the most consistently reported predictor of psychological distress appears to be poor pre-operative counseling about the procedure and its effects. ${ }^{10,31,35}$ This is compounded by the fact that many men, particularly in developing countries, have a very limited understanding of vasectomy, as well as negative attitudes towards it. $38-40$ Furthermore, fear of the unknown, which can result from poor knowledge, has been linked to anxiety about vasectomy. ${ }^{41}$ It is noteworthy that the studies reporting high rates of post-vasectomy psychological and sexual complications have all come from developing countries, where poor communication between providers and patients is more likely, ${ }^{20-25,31}$ and myths relating to adverse health effects are common. $22,38,39$

In our patient, several of these factors were operative. His family had a generally negative view of vasectomy and its impact on health, and he did not receive adequate pre-procedure counseling. This led to an acute episode of anxiety following the procedure, ${ }^{41}$ as well as a chronic depression, 31 associated with medically unexplained physical symptoms. ${ }^{24}$ He failed to respond to antidepressant monotherapy, further underlining the importance of psychosocial factors in his case. It is unknown to what extent his family history of mental illness may have acted as a vulnerability factor.

Given the findings summarized above, it is clear that pre-procedure screening and appropriate counselling - including the involvement of his family in the consent process - may have minimized or even prevented this patient's depression. ${ }^{6}$ This has been demonstrated by a study from Iran, ${ }^{42}$ as well as prospective data showing that good pre-vasectomy counseling significantly reduces the rates of post-operative depression and other psychological complications.43,44 Treatment in this patient would include a combination of cognitive and behavioral approaches, focusing on his beliefs regarding vasectomy and his resultant emotional responses. Behavioral methods would help the patient to resume normal functioning, as well as minimize the impact of his physical symptoms. Throughout the course of treatment, his spouse and family would also be involved in this discussion, and should be given a chance to express their regrets about the procedure.

\section{Conclusions}

In conclusion, psychological complications following a vasectomy - though relatively uncommon - are especially likely to occur in the absence of proper counseling and information regarding the procedure, as well as in individuals with pre-existing psychological vulnerability or marital discord. Careful screening of candidates for vasectomy, and the provision of adequate, culturally-sensitive counseling, can minimize this risk, as well as exclude those who would be unlikely to benefit from the procedure. Further large-scale studies, using validated rating scales or diagnostic schedules, would provide clear estimates of the scope of these problems, particularly anxiety and depression. 


\section{References}

1. Phillip T, Guilleband J, Budd D. Complications of vasectomy: review of 16000 patients. Br J Urol 1984;56:745-8.

2. Tandon S, Sabanegh E Jr. Chronic pain after vasectomy: a diagnostic and treatment dilemma. Br J Urol 2008;102:166-9.

3. Sethi BB. Family planning and mental health. Indian J Psychiatry 1981;23:101-3.

4. Schover LR. Psychological factors in men with genital pain. Cleve Clin J Med 1990;57:697-700.

5. Ziegler FJ, Rodgers DA, Prentiss RJ. Psychosocial response to vasectomy. Arch Gen Psychiatry 1969;21:46-54.

6. Wolfers H. Psychological aspects of vasectomy. BMJ 1970;4:297-300.

7. Ellinwood CN. Vasectomy: an argument for its therapeutic use in certain mental diseases and as a means of diminishing crime and the number of criminals. Calif State J Med 1904;2:60-1.

8. Bachrach S. In the name of public health Nazi racial hygiene. N Engl J Med 2004; 351:417-20.

9. Lyons HA. Psychological screening for vasectomy. Ulster Med J 1978;47:177-85.

10. Savage P. Vasectomy and psychosexual damage. Health Serv Rep 1972;87:803-4.

11. Goldsmith A, Goldberg RJ. Psychosocial aspects of vasectomy in Latin America. J Sex Res 1974;10:278-92.

12. Weisberg E. Psychological sequelae of vasectomy. Fam Plann Inf Serv 1980;1:113.

13. Goldsmith A, Goldberg R, Echeverria G. An in-depth study of vasectomized men in Latin America: a preliminary report. J Reprod Med 1973;10:150-5.

14. Santiso R, Pineda MA, Marroquín M, Bertrand JT. Vasectomy in Guatemala: a follow-up study of five hundred acceptors. Soc Biol 1981;28:253-64.

15. Hofmeyr DG, Greeff AP. The influence of a vasectomy on the marital relationship and sexual satisfaction of the married man. $\mathrm{J}$ Sex Marital Ther 2002;28:339-51.

16. Smith A, Lyons A, Ferris J, et al. Are sexual problems more common in men who have had a vasectomy? A population-based study of Australian men. J Sex Med 2010;7:736-42.

17. Kohli KL, Sobrero AJ. Vasectomy: a study of psychosexual and general reactions. Fam Plann Resume 1977;1:184-7.

18. Bertero E, Hallak J, Gromatzky C, et al. Assessment of sexual function in patients undergoing vasectomy using the international index of erectile function. Int Braz $\mathrm{J}$ Urol 2005;31:452-8.

19. Buchholz NP, Weuste R, Mattarelli G, et al. Post-vasectomy erectile dysfunction. J Psychosom Res 1994;38:759-62.

20. Sethi BB, Nathawat SS. Personality and family planning. Indian J Psychiatry 1973;15:20-8.

21. Dias PL. The long-term effects of vasectomy on sexual behavior. Acta Psychiatr Scand 1983; 67: 333-8.

22. Wolfers H, Subbiah N, Ariffin Bin Mazurka. Psychological aspects of vasectomy in Malaysia. Soc Biol 1973;20:315-22.

23. Srivastava PD. Post-vasectomy sexual disturbances and their treatment. Probe 1973;12:183-6.

24. Wig NN, Singh S, Sahasi G, Isaac P. Psychiatric symptoms following vasectomy. Indian J Psychiatry 1970;12:169-76.

25. Sawhney N, Nathawat SS, Sethi BB. A longitudinal study in family planning. Indian J Psychiatry 1970;12:155-68.

26. Howard G. The quality of marriage before and after vasectomy. Br J Sex Med 1979;6:13-4.

27. Shain RN, Miller WB, Holden AE, Rosenthal M. Impact of tubal sterilization and vasectomy on female marital sexuality: results of a controlled longitudinal study. Am J Obstet Gynecol 1991;164:76371.

28. Maschhoff TA, Fanshier WE, Hansen DJ. Vasectomy: its effect upon marital stability. J Sex Res 1976;12:295-314.

29. Miller WB, Shain RN, Pasta DJ. The preand poststerilization predictors of poststerilization regret in husbands and wives. J Nerv Ment Dis 1991;179:602-8.

30. Granitsiotis P, Kirk D. Chronic testicular pain: an overview. Eur Urol 2004;45:430-6.

31. Luo L, Wu SZ, Zhu C, et al. Psychological long-term effects of sterilization on anxiety and depression. Contraception 1996;54:345-57.
32. Jackson LN, Avant P. Vasectomy: a followup of two thousand men. J Roy Coll Gen Pract 1982;32:172-3.

33. Goldstuck ND, England MJ, Dukes IA. Attitudes to vasectomy among rural and urban African men. Adv Contracept Deliv Syst 1988;4:235-41.

34. Dibaba A. Rural men and their attitude towards vasectomy as means of contraception in Ethiopia. Trop Doct 2001;31:100-2.

35. Philliber SG, Philliber WW. Social and psychological perspectives on voluntary sterilization: a review. Stud Fam Plann 1985;16:1-29.

36. Bloom LJ, Houston BK. The psychological effects of vasectomy for American men. J Genet Psychol 1976;128:173-82.

37. Horenstein D, Houston BK. The effects of vasectomy on postoperative psychological adjustment and self-concept. J Psychol 1975;89:167-73.

38. Nishtar NA, Sami N, Faruqi A, et al. Myths and fallacies about male contraceptive methods: a qualitative study amongst married youth in slums of Karachi, Pakistan. Glob J Health Sci 2012;5:84-93.

39. Saoji A, Gumashta R, Hajare S, Nayse J. Denial mode for vasectomy among married men in central India: causes and suggested strategies. J Psychol Psychother 2013;3:120.

40. Shih G, Dubé K, Sheinbein M, et al. He's a real man: a qualitative study of the social context of couples' vasectomy decisions among a racially diverse population. Am $\mathrm{J}$ Mens Health 2013;7:206-13.

41. Sandlow JI, Westefeld JS, Maples MR, Scheel KR. Psychological correlates of vasectomy. Fertil Steril 2001;75:544-8.

42. Nikkhooi A, Ekhlasi A, Davasaz Irani R. The effect of counselling on reduction of depression after vasectomy and tubal ligation. Iran J Psychiatry 2004;9:43-8.

43. Cass AS. Unsatisfactory psychosocial results of vasectomy resulting in modification of preoperative counseling. Urology 1979;14:588-91.

44. Ehn BE, Liljestrand J. A long-term followup of 108 vasectomized men. Good counselling routines are important. Scand J Urol Nephrol 1995;29:477-81. 